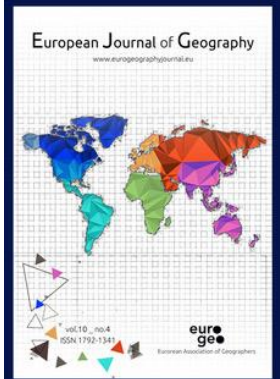

European Journal of Geography

Volume 11, Issue 1, pp. 163 - 187

Article Info:

Received: 26/08/2020; Accepted: 19/10/2020

Corresponding Authors: * abartzok@mail.ntua.gr, ** yphotis@mail.ntua.gr

https://doi.org/10.48088/ejg.a.bar.11.1.163.187

\title{
Does neighborhood walkability affect ethnic diversity in Berlin? Insights from a spatial modeling approach
}

\author{
Alexandros BARTZOKAS-TSIOMPRAS ${ }^{1^{*}}$, \\ Yorgos N. PHOTIS ${ }^{* *}$
}

${ }^{1}$ National Technical University of Athens, Greece

Keywords:

spatial regression, GWR,

OLS,

walkability, ethnic diversity, entropy index, Berlin, migrants

\begin{abstract}
Prior research has reported that people living in more walkable places gain significant health, and environmental sustainability benefits. However, the positive impacts of walkable urbanism are not often inclusive and might affect minority groups. On this basis, this paper develops a composite GIS-based walkability measure (0-1) for Berlin metro area and investigates the association of walkable neighborhood design with ethnic diversity (i.e., Entropy Index). We explore this relationship by applying spatial regression models (i.e., OLS, GWR), while we control the effects of traffic-related air pollution (i.e., NO2), building height, and children density. Our findings suggest that for the total of 447 Berlin neighborhoods which were examined only one out of three had walkability scores greater than 0.5 as well as that community ethnic diversity is negatively related to walkability $(\beta=-0.159, p<0.01)$.
\end{abstract}

The publication of the European Journal of Geography (EJG) is based on the European Association of Geographers' goal to make European Geography a worldwide reference and standard. Thus, the scope of the EJG is to publish original and innovative papers that will substantially improve, in a theoretical, conceptual or empirical way the quality of research, learning, teaching and applying geography, as well as in promoting the significance of geography as a discipline. Submissions are encouraged to have a European dimension. The European Journal of Geography is a peer-reviewed open access journal and is published quarterly. 


\section{INTRODUCTION}

Walkability is a composite built environment measure and refers to the capacity of neighborhoods to create traversable, compact, safe, and physically-enticing places for walking (Forsyth, A., 2015). During the last decades the benefits of walkable communities on public health (Stevenson, M., et al., 2016, Nieuwenhuijsen \& Khreis, 2016), housing markets (Gilderbloom et al., 2015), and environmental sustainability (Frank et al., 2006,Frank et al., 2010a) have been widely reported. For neighborhood and equity advocates though, positive effects created by dense and walkable urbanism are not often seen as good news for their communities, mainly due to increasing concerns about the displacement of socio-vulnerable groups (Quastel et al., 2012). To this end, there is evidence that some walkable environments tend to escalate spatial inequities (Bartzokas-Tsiompras et al., 2020) and people of certain race or ethnic minority groups are displaced in disproportionally more car-dependent locations (Knight et al., 2018). Other authors have been warning us about differences in pedestrian streetscapes between communities of contrasting socio-demographic and racial characteristics (Thornton et al., 2016). Moreover, such socio-spatial implications are often caused by increases that walkability poses in local housing markets (Gilderbloom et al., 2015). Since, by improving urban form and pedestrian-friendliness of neighborhoods, gentrification processes might also come up, social sorting actions should be prevented (Quastel et al., 2012).

Although, many studies have provided evidence that walkability increases social capital (Leyden, 2003) and the sense of community (Lund, 2002), there is little evidence of the relationship between neighborhood walkability and ethnic diversity (Duncan et al., 2012). Especially in Europe, the relevant literature and number of studies is limited. The overwhelming majority of walkability research has been mainly carried out in North America, and a great focus has been made in health and environmental impacts of walkability features (Wang \& Yang, 2019). Although prior studies have shown that most of the walkability measures are positively correlated to non-motorized trips, physical activity, and better health outcomes (Brownson et al., 2009, Frank et al., 2010a), we do not have enough evidence about the walkability fluctuations when it comes to local communities with diverse ethnic backgrounds. Consequently, if health and environmental benefits of pedestrian-oriented communities are not distributed in an inclusive way, then walkability promotion will not create sustainable outcomes for all (Talen, 2012).

In this paper we study the metropolitan area of Berlin and to this end, we develop a GIS-based walkability index. The focal point of this research is to analyze the interrelationship of walkability and ethnic diversity. Berlin is a rapidly urbanizing city that aims to become a top European pedestrian-oriented metropolis (Senate Department for Urban Development \& the Environment, 2015). However, the city still deals with problems such as traffic-related air pollution (Senate Department for Urban Development \& the Environment, 2017), housing affordability issues (Kersting et al., 2017) and presents high rates (19\% of total population) of migrant and refugee minority groups (Amt für Statitstik Berlin Brandenburg, 2019). All of these issues make Berlin a perfect case study for our research.

In essence, this work adds new empirical evidence in environmental justice and walkability literature, since it utilizes both global (e.g., OLS) and local (e.g., GWR) 
spatial regression models to investigate the impact of good and walkable urbanism upon a fundamental element of social sustainability in cities namely, its neighborhoods ethnic diversity. The applied multiple regression modeling approach also controls the effects of traffic-related air pollution, the building height, and children density. In the next section, we elaborate on previous research findings regarding the impacts of walkability on neighborhoods sustainability as well as review and comment on the varying methodological approaches for walkability measures. Section 3 presents information about the study area while section 4 describes the methodological framework and data preparation processes. Section 5 presents the results of the application of our methodological approach and finally section 6 concludes the paper with the discussion and insights on the major findings of this work.

\section{LITERATURE REVIEW}

\subsection{Walkability: From sustainability \& health benefits to spatial inequalities}

A large body of research has reported significant positive associations of better health outcomes with people living in more walkable places (Stevenson et al., 2016, Sallis et al., 2016, Frank et al., 2010a, Brownson et al., 2009, Grasser et al., 2017, Frank et al., 2005). For instance, Stevenson et al. (2016) found that walkable urbanism strategies that limit car commuting and encourage active travel, can have overall health gains of 420-826 disability-adjusted life-years (DALYs) per 100.000 population. Also, the literature has indicated that urban form improvements can promote walkability and in turn we can achieve better environmental sustainability results (Frank et al., 2010a, Frank et al., 2006). On this basis, Frank et al. (2006) provided evidence that more walkable neighborhoods can decrease vehicle miles traveled by $6.5 \%$ and reduce NOx emissions by $5.6 \%$. Other authors reported positive effects of walkability in housing markets, crime, and foreclosure (Gilderbloom et al, 2015). On the other hand, some researchers indicated contradictory results and suggested that walkability has significant impacts on housing prices only if it is included in better-specified models that account for other neighborhood attributes (Boyle et al., 2014), while others demonstrated that walkability tends to create criminogenic environments (Dong, 2017).

Building cosmopolitan and socially diverse cities with walkable public spaces has been acknowledged to be a key factor for social equality in the city (Talen, 2012). Having said that, prior research on the effects of walkable places on spatial justice and social cohesion has produced some conflicting results. Although, advocates claim that walkability increases social capital (Leyden, 2003), the sense of community (Lund, 2002), and supports the mobility choices of the most vulnerable individuals (Speck, 2018), the real practice has presented some striking socioeconomic inequalities. Knight et al. (2018) found that some disaduantaged groups with no cars, such as low-income, unemployed or minority groups, tend to concentrate in areas of poor walkability, while in walkable areas the housing prices are soaring up. Quastel et al. (2012) argued that walkable place characteristics that enhance environmental sustainability are also associated with gentrification and social exclusion due to rising housing prices. Riggs (2016) used regression modeling and contoled the effects of income, education, and social networks, to report that walkable housing in San Francisco Bay Area is not inclusive for people of certain race (i.e., Blacks), as they live in less walkable places. 
Thornton et al., (2016) found that income and race-based disparities in pedestrian streetscapes exist and these differences are more profound in residential areas than in mixed-used developments. Bartzokas-Tsiompras et al. (2020) used a virtual micro-scale walkability audit tool to demonstrate that pedestrian-friendliness characteristics in eight European downtown areas are not equality distributed among downtowners. On the other hand, Duncan et al., (2012) used regression models to investigate if spatial inequalities in walkability are related to residential segregation. Althought, they found segregation in Black communities of Boston, MA, they did not report any association of neighborhood socio-demographic characteristics with walkability. Intrestingly, a study from Madrid supported that areas with higher neighborhood socioeconomic status presented urban forms of low walkability and this outcome was not evident in newly built or gentrified areas (Gullón et al., 2017). To our best knwoledge, no study so far has directly investigated the relationship of a walkability composite measure with local ethnic heterogeneity. Hence, this paper contributes new knowledge by begging the question of whether mixed migrant communities are accompanied and supported by walkable neighborhood design.

\subsection{Walkability Measures}

In practice, although several walkability measurement approaches have been proposed, either from the health sciences or environmental and urban planning sciences (Wang \& Yang, 2019), there is no global consensus about a universal and standard protocol in walkability instruments (Brownson et al., 2009, Forsyth, 2015, Wang \& Yang, 2019). Overall, two main categories of walkability indicators exist. Firstly, the macro-level and objectively measured walkability indices, and secondly the micro-level (more subjective) walkability audit tools. Measures of the first category help to explore cardependent communities across an urban region (Bartzokas-Tsiompras \& Photis, 2017), while micro-level walkability audits (Bartzokas-Tsiompras et al. 2020, BartzokasTsiompras et al. 2021) allow us to capture the pedestrian 'friendliness' level of the local streetscape environment. However, in this section we will emphasize only on macrolevel indicators since micro-level audit tools are not in the scope of this study. Further details in micro-level audit tools can be found in the work of Brownson et al. (2009).

Macro-level walkability indicators are popular instruments in many health and transport planning research studies (Wang \& Yang, 2019). They use readily available GIS datasets and require simple computation techniques. These indices have been inspired by prior research findings on the "Seven-Ds" theoretical framework (i.e., Density, Diversity, Design, Destination accessibility, Demand management, Distance to transit, and Demographics) and the power of this concept to encourage non-motorized trips (Ewing \& Cervero, 2010). Therefore, in this kind of measures the walkable neighborhood design is analyzed mostly by variables such as housing density, land use mix, intersection density, and/or retail floor area ratio (Wang \& Yang, 2019, Frank et al., 2005, Frank et al., 2010, Grasser et al. 2017). Practically, standardized values of density-and-street-connectivity-related parameters are aggregated linearly using equal (Grasser et al., 2017) or weighted aggregation schemes (Bartzokas-Tsiompras \& Photis, 2017). For example, Grasser et al. (2017) demonstrated that a European GISbased walkability indicator is positively associated either with walking or cycling for 
transport. Frank et al. (2005) indicated that persons living in the highest walkability quartile are 2.4 times more likely than people in the lowest quartile to have more than 30 minutes of moderate physical activity per day. However, this empirical validation process of walkability results with real walking or physical activity data is not often carried out and this is a major limitation for several walkability indices.

More complex operationalization walkability measurement approaches at macrolevel have been also investigated. For instance, Weiss et al. (2010) involved a scale rating system in their Objective Walkability Index (OWI), Bartzokas-Tsiompras \& Photis (2017) used the Borda count method to define walkability weights from a national-wide questionnaire, while Habibian \& Hosseinzadeh (2018) and Deng et al. (2020) suggested a statistical weighting and aggregation scheme based on Principal Components Analysis (PCA). Interestingly, Su et al. (2019), proposed a 13-item walkability index that applies the catastrophe theory model and accordingly reduces the uncertainty and subjectivity of other conventional, often arbitrary, weighting and aggregation schemes. Other also popular and validated measurement approaches opted to assess the ease of walking accessibility to multiple amenities located nearby a given street address (i.e., Walk Score ${ }^{\circledR}$ ) (Duncan et al., 2011). In other studies, researchers used space syntax analysis (Paraskeuopoulos et al., 2019) that refers to one aspect of walkability, namely street connectivity (Koohsari et al., 2019a). For instance, Koohsari et al. (2019a), proposed a non-data-intensive Space Syntax Walkability (SSW) framework that connects urban form (i.e., angular street integration metric) and urban function (i.e., population density) with walking for transport. An empirical study from Australia (Koohsari et al., 2019b) validated the results of a SSW index and found that the scores are positively correlated $(r=0.76)$ either with increased walking for transport or with a conventional four-element GIS-index (Frank et al., 2010b).

A detailed review and bibliometric analysis in neighborhood walkability measures can be find in Wang \& Yang (2019). Yet, macro-level GIS-based walkability indicators present high heterogeneity in their variables, methods and data sources, which in turn limit their comparability and the generalizability of their research outcomes.

\section{STUDY AREA}

The metropolitan capital region of Germany consists of two parts, Berlin and the Brandenburg. In this study, we analyze the inner metropolitan area $\left(891 \mathrm{~km}^{2}\right)$ which has nearly up to 3.6 million inhabitants (Amt für Statitstik Berlin Brandenburg, 2019). Berlin hosts more than 180 nationalities and about $19 \%$ of the total population is foreigners. The majority of foreign population is male (51.8\%) and between 25 and 65 years old (68\%) (Amt für Statitstik Berlin Brandenburg, 2019). Also, 19,2\% of the total population is over 65 years old, whereas $16,5 \%$ of the inhabitants is under 18 years old (Amt für Statitstik Berlin Brandenburg, 2019).

Since 1990 Berlin has experienced an outward expansion, where more people have chosen to live in the surroundings than moving in the center (Senate Department for Urban Development \& the Environment, 2017). Furthermore, 49\% of Berliners live in high-rise buildings, and roughly $50 \%$ of them prefer to live at the city outskirts (Rode et al., 2015) while at the same time, $85 \%$ of residents in Berlin reside in rental housing (Senate Department for Urban Development \& the Environment, 2015), and the renting costs between 2011-2016 has been skyrocketed by 75,9\% (Kersting et al., 2017). 
Regarding the recent modal split data (2018) we know that $28 \%$ of people use cars, $32 \%$ walks, $13 \%$ are cyclists, and $27 \%$ use transit (Senate Department for the Environment, Transport \& Climate Protection, 2019). Finally, the city in the new spatial strategy for 2030 (Senate Department for Urban Development \& the Environment, 2015) has expressed its interest to invest in sustainable urban mobility solutions so as to become one of the most walkable cities in Europe.

\section{MATERIALS \& METHODS}

In this section we firstly introduce the data preparation procedures for the dependent (ethnic mix) and the four exploratory variables, and secondly we discuss the theoretical aspects and assumptions of spatial regression modeling.

\subsection{Berlin Walkability Index (BWI)}

The Berlin Walkability Index (BWI) is a GIS-based and quantitative walkability measure, consisted by four long-term morphological ingredients of the built environment (see Table 1.a). The scores of this index are reported at the Lebensweltlich orientierte Räume (LOR) spatial unit level, and the values range between 0 and 1. Thus, scores near to one indicate a dense and well-connected urban environment where people can do most of their daily errands on foot, while scores near to zero demonstrate unsustainable and mainly car-dependent communities. Since this measure is not validated with objectively measured physical activity data, we hypothesize that its outcomes are also positively correlated with walking propensity and decreased cardependent lifestyles. Similar composite measures in other studies (Grasser et al., 2017, Frank et al., 2005) have reported links with increased walking, while other evidences demonstrated that the effects of walkability scores on physical activity outcomes are not moderated by ethnic/race backgrounds (Twardzik, et al., 2019) or age/gender.

The first variable pertained to the street network connectivity and included the roads intersection density (Int_Den) measure. This variable was based on Frank's et al. (2010b) index and it had a double-weight in the final equation. Particularly, we used official street centerline data and we counted only street nodes with three or more links. However, motorways were initially excluded from the analysis, since they are not considered as walkable street segments. The second parameter was the population density (inhabitants per sq.km) (Pop_Den) and symbolized the capacity of each neighborhood to shorten the distances between people and the destinations they need to reach (Frank et al. 2010b, Grasser et al., 2017). The third parameter described the proportion of mixed land-uses (Mixed_LU.) and it was also previously contained in the Graz Walkability Index (Grasser et al., 2017). A high share of mixed urban enuironments is a critical factor in walkable urbanism, as the mixed functions generate a greater range of walkable destinations (Ewing \& Cervero, 2010). In practice, to calculate this variable we used the online services of Berlin Environmental Atlas and the shapefiles for the actual land-uses of the built-up areas. The last and fourth variable of the BWI pertained to the density of public transit stops and stations, which is a strong predictor 
of higher pedestrian activity (Lai \& Kontokosta, 2018), as well as it provides alternative and sustainable transportation choices to people (Speck, 2018). The official GTFS dataset of the local metropolitan transport authority (VBB) was used to get all the transit locations in the city. Technically, we applied the Kernel Density Estimator to transit stops locations in ArcGIS for Desktop U.10.3 (ESRI, Redlands, CA) so as to calculate the mean number of transit facilities per sq.km (Stops_Den). All four variables were initially normalized, using the Min-Max method, and the final score was the result of the formula demonstrated in eq.1. Table 1 presents briefly the list of all BWI variables and their data source.

$$
\mathrm{BWI}=\left[2 *\left(I n t \_D e n\right)+P o p \_D e n+\text { Mixed_LU }+ \text { Stops_Den }\right] / 5 \quad \text { eq.(1) }
$$

Table 1.a. Variables of the BWI GIS-based index

\begin{tabular}{|c|c|c|c|c|c|}
\hline Data & Unit & $\begin{array}{l}\text { Geometry } \\
\text { Calculations }\end{array}$ & Time & $\begin{array}{l}\text { Spatial } \\
\text { Unit }\end{array}$ & Data Source \\
\hline Population Density & $\begin{array}{l}\text { Inhabitant } \\
\text { s per } \\
\text { sq.km }\end{array}$ & Polygons & 2018 & LOR $^{*}$ & $\begin{array}{l}\text { Amt für } \\
\text { Statistik Berlin- } \\
\text { Brandenburg }\end{array}$ \\
\hline Intersection Density & $\begin{array}{l}\text { Nodes(s) } \\
\text { per sq.km }\end{array}$ & $\begin{array}{l}\text { From points to } \\
\text { polygons }\end{array}$ & 2014 & LOR* $^{*}$ & $\begin{array}{l}\text { Berlin } \\
\text { Enuironmental } \\
\text { Atlas - Official } \\
\text { Road Network }\end{array}$ \\
\hline $\begin{array}{l}\text { Proportion of Mixed } \\
\text { Land Uses }\end{array}$ & $\begin{array}{l}\% \text { of } \\
\text { Mixed } \\
\text { land-uses }\end{array}$ & Polygons & 2015 & LOR $^{*}$ & $\begin{array}{l}\text { Berlin } \\
\text { Environmental } \\
\text { Atlas - Actual } \\
\text { Use of Built-up } \\
\text { Areas }\end{array}$ \\
\hline Transit Stops Density & $\begin{array}{l}\text { Stops per } \\
\text { sq.km }\end{array}$ & $\begin{array}{l}\text { From points to } \\
\text { polygons }\end{array}$ & 2020 & LOR* & $\begin{array}{l}\text { GTFS Data - } \\
\text { Verkehrsuerbu } \\
\text { nd Berlin- } \\
\text { Brandenburg }\end{array}$ \\
\hline
\end{tabular}

(*) Lebensweltlich orientierte Räume

Since the scope of this research is not to analyze extensively the spatial patterns of walkability in Berlin, we undertook only basic spatial analysis methods. To that end, we performed hot spot analysis, using local Getis-Ord Gi* statistics (Ord \& Getis, 1995), to illustrate and measure the spatial variation of scores in the study area. Similarly, this method was also applied in the other variables too. More technical details of hotspot analysis in ArcGIS for Desktop software can be seen online by ESRI (2020c).

\subsection{Other data preparation and data sources}

To run the spatial regression models except of the BWI we also needed to prepare the data for extra four variables (see Table 1.b). First, to measure ethnic diversity (dependent variable) we calculated an Entropy Index, based on the D4I big dataset (Tintori et al., 2018). D4l is a spatial population grid at very high spatial resolution (100 $x 100 \mathrm{~m}$ ) for eight European countries that shows the concentration of migrants in cities at three levels of aggregated geographies, i.e., by specific country of origin, per continent, and EU versus not-EU origin country. D4I has been created through a spatial 
disaggregation of official 2011 national censuses and it was promoted initially to researchers by the Joint Research Center (J.R.C) of the European Commission in 2017 (see in Bartzokas-Tsiompras \& Photis (2019) an example of an application of D4l in transit accessibility analysis of migrant communities). In our study we used the D4I data by country of origin and we aggregated each population group per each LOR spatial unit. Next, having the analytical populations per country of origin and per LOR spatial unit we applied Thail's Entropy Index formula (Theil \& Finezza, 1971) on the open source software Geo-Segregation Analyzer v.1.2 (Apparicio et al., 2014) in order to measure the diversity of migrant communities. Values near to 1 mean high ethnic heterogeneity, while values near to 0 mean ethnic homogeneity. Further methodological details about other alternative ethnic diversity or segregation measures can be found in the work of White (1986).

Table 1.b Data variables description

\begin{tabular}{|c|c|c|c|c|}
\hline Variable & $\begin{array}{l}\text { Geometry } \\
\text { Calculations }\end{array}$ & Time & Spatial Unit & Data Source \\
\hline $\begin{array}{l}\text { 1. Ethnic diversity - } \\
\text { Entropy Index* }\end{array}$ & $\begin{array}{l}\text { From points to } \\
\text { polygons }\end{array}$ & 2011 & $\begin{array}{l}\text { LOR - } \\
\text { Lebensweltlich } \\
\text { orientierte Räume }\end{array}$ & $\begin{array}{l}\text { D4I - JRC, European } \\
\text { Commission }\end{array}$ \\
\hline $\begin{array}{l}\text { 2. Density of } \mathrm{NO}_{2} \text { air } \\
\text { emissions }{ }^{* *}\end{array}$ & $\begin{array}{l}\text { From lines to } \\
\text { polygons }\end{array}$ & 2015 & $\begin{array}{l}\text { LOR - } \\
\text { Lebensweltlich } \\
\text { orientierte Räume }\end{array}$ & $\begin{array}{l}\text { Berlin Environmental Atlas } \\
\text { - Official Road Network }\end{array}$ \\
\hline 3. Child density** & Polygons & 2018 & $\begin{array}{l}\text { LOR - } \\
\text { Lebensweltlich } \\
\text { orientierte Räume }\end{array}$ & $\begin{array}{l}\text { Amt für Statistik Berlin- } \\
\text { Brandenburg }\end{array}$ \\
\hline
\end{tabular}

* One asterisk describes a dependent variable.

** Two asterisks denote an exploratory variable. An exploratory variable is also the BWI in Table 1.a

Regarding the average building height variable we utilized open-source raster data, at high spatial resolution (i.e., $10 \mathrm{~m}$ ) from European Environmental Agency's (EEA) Urban Atlas programme. Urban Atlas, provides height information for all European capital cities, produced by remote sensing processing on IRS-P5 stereo images and other datasets such as the digital surface model, the digital terrain model and the normalized digital surface model (https://land.copernicus.eu/local/urban-atlas/building-height2012, Accessed: 22/09/20). Higher building height, means higher levels of compact urban development, where job opportunities, population and active environments are more intensive (Lai \& Kontokosta, 2018). Therefore, in our study we calculated average building height per LOR spatial unit. The next variable refers to the density of the harmful and traffic-related air emissions, i.e., $\mathrm{NO}_{2}$, and indicates the local quality of living. The data derived from the online services of Berlin Environmental Atlas and specifically we used the traffic-related air pollution data per street segment on 2015. Average density values of $\mathrm{NO}_{2}$ per sq. $\mathrm{km}$ were computed using the Kernel Density Estimator in ArcGIS for Desktop U.10.3. The last variable involved the density of children population. Especially, we used official census data (2018) and the population classes up to 18 years old to calculate per LOR spatial unit the number of children per sq.km. Children density highlights the presence of families and a system of kid-related facilities, such as schools or playgrounds, which are attractive for refugee and migrant families, as well. 


\subsection{Spatial Regression Modeling}

Conventional spatial analysis methods allow us to understand general questions of where a phenomenon is taking place, however spatial regression methods help us to get a better understanding of the reasons why a phenomenon is happening, of the factors causing it and even to explore spatial associations in order to make better decisions. In this framework, spatial linear regression analysis includes four major models, namely the well-known Ordinary Least Squares (OLS), the Spatial Lag, the Spatial Error, and the Geographically Weighted Regression (GWR) (Fotheringham et al., 2002). The latter model is the only one of the four that has a local or geographic nature, while the first three has a global character. In this study, as a starting point we applied an OLS method to test the good-model-fit of the entire dataset and in turn we continued with GWR modeling for two reasons. First, the global model does not account for spatial heterogeneity, and second we aimed to compare the two models and in turn to find out the best modeling solution. Except of the aforementioned selected independent variables we also performed previously exploratory regressions with other data such as mean Airbnb prices, elderly density, passenger cars per 1000 people, unemployment rates, distance from city center (Alexanderplatz), NDVI (green areas), share of women, density of primary roads, density of pedestrian streets and paths, streets density, tree density, and crime incidents density. All of these variables presented problematic regression characteristics, such as high multicolinearity issues or statistically notsignificant coefficients.

\subsubsection{Ordinary Least Squares (OLS)}

The OLS model is a fundamental linear regression method (eq.2) in econometrics and it have been widely used in numerous research problems in environmental, economic, and demographic studies. Specifically, an OLS model is simply expressed as:

$$
y=\beta_{0}+\sum_{i=0}^{p} \beta_{i} x_{i}+\varepsilon \quad \text { eq.(2) }
$$

Where $y$ is the dependent variable, $\beta_{0}$ is the intercept value, $i$ is the number of independent variable(s), $\beta_{i}$ is the coefficient for the independent variable $x_{i}$ and $\varepsilon$ is the random error. However, a number of modeling assumptions should be checked to validate the robustness of the OLS method. First, Adjusted R-Squared and Akaike's Information Criterion (AICC) analyze the model performance, while Variance Inflation Factor (VIF) values greater than 7.5 indicate multicollinearity among the independent variables. Moreover, probabilities (or robust probability, dependent on Koenker statistic result) highlight statistically significant estimated coefficients. Next, using statistically significant $(p<0.01)$ Joint F-Statistic and Joint Wald Statistic, we understand if the explanatory variables in the model are effective, while for data heteroscedasticity and stationarity issues we examine if the Koenker (BP) statistic is statistically significant $(p<0.01)$. If model predictions are biased, and thus the residuals are not normally distributed, then the Jarque-Bera Statistic is statistically significant $(p<0.01)$. Finally, since OLS regression requires the residuals to be spatially independent, we use Global Moran's I residuals test to investigate their spatial pattern. The Global Moran's I is a 
widely used test for spatial autocorrelation that evaluates if a phenomenon is clustered, random, or dispersed. The result of this test produces both a z-score and a pvalue to assess the significance of the Moran's I index. More details about this spatial dependence index can be found in Getis \& Ord (1992). Therefore, a Global Moran's I residuals test that is clustered or dispersed, makes the OLS model biased and perhaps another modeling approach should be examined (e.g., Spatial Lag, Spatial Error, GWR).

\subsubsection{Geographically Weighted Regression (GWR)}

The GWR model is a recent regression modeling approach that was originally proposed by Brundson et al. (1996) for spatial point data. A GWR regression concept extends the conventional OLS model and allows the associations between the dependent and exploratory variables to change across space, as it develops different least squares equations with specific characteristics for every spatial location in the data. Hence, GWR takes into account the spatial nonstationarity within the data and help us to get new insights about the factors (independent variable) driving the location of a particular phenomenon (dependent variable). Practically, each local OLS equation for the dependent variable is based on the independent variables that fall within the bandwidth of each target location, and the bandwidth is calculated either manually or it can be defined by a statistical process. However, each observation is weighted by a decreasing function of its distance to the estimation location. More technical and analytic details about the formulas and the application of a GWR model can be found in Fotheringham et al. (2002).

In this study a set of significant methodological choices have been made in the application of the GWR regression model in ArcGIS for Desktop U.10.3 (ESRI, Redlands, CA). Firstly, the spatial weight matrix was based on an adaptive (Gaussian) kernel approach, because the observations were not distributed in a fixed distance. Secondly, the bandwidth for the number of neighbors, meaning the neighboring polygons beyond which the weight of the observations is zero, was set to minimize the value of the AICc. Additionally, $t$-Statistic values was calculated to determine the statistical significance of each local estimated coefficient. Finally, the residuals of the GWR model was also tested for spatial autocorrelation using again the Global Moran's I test. Performance comparisons between the two models were based on the Adjusted $\mathrm{R}^{2}$ values, the reduction or not of the AICC value in GWR, and the spatial dependence of the residuals. Methodological and technical details for GWR and OLS computations in ArcGIS for Desktop U.10.3 software can be found online in ESRI (2020a) and ESRI (2020b).

\section{RESULTS}

In this section we firstly present the results of the indicators processing and calculation and secondly, we illustrate the findings from the OLS and GWR models.

\subsection{Dependent \& Independent Variables}


As can be seen in Table 3, all independent variables had a moderate to good positive Pearson correlation with the ethnic diversity index (dependent variable). The strongest association of ethnic heterogeneity, however, was found with the average building height $(r=0.601)$, while the weaker relationship was highlighted with walkability $(r=0.468)$. The entropy index ranged (Table 3) between 0 (e.g., Lietzengraben, Messegel, Park Nord), indicating communities with homogenous ethnic groups, to 0.38 (Motardstr.), which were the most diverse neighborhoods. Namely, the highest average entropy value demonstrated in the central borough of Mitte (0.24) and the Neukoln (0.19), but to the contrary the lowest average values were demonstrated in the eastern boroughs of Treptow-Kopenick (0.07) and Pankow (0.08). Also, about 51.7\% of the total population lives in areas where the entropy index is higher than the median value (0.14). In Fig.1.a the entropy values are presented in a quantile map, and the striking difference in ethnic mix between western and eastern berlin communities is quite obvious (Fig.1.b).

Table 2. Descriptive statistics per variable

\begin{tabular}{llllllll}
\hline $\mathbf{N}=\mathbf{4 4 7}$ & Min. & Max. & $\mathbf{1}^{\text {st }} \mathbf{Q u}$. & Median & $\mathbf{3}^{\text {rd }} \mathbf{Q u}$. & Mean & s.d \\
\hline Ethnic diversity* & 0 & 0.38 & 0.09 & 0.14 & 0.18 & 0.15 & 0.07 \\
Walkability & 0 & 0.88 & 0.25 & 0.36 & 0.50 & 0.37 & 0.18 \\
$\mathrm{NO}_{2}$ Emissions Density & 0.23 & 20.37 & 35.81 & 6.01 & 9.22 & 6.75 & 4.11 \\
Children Density & 0 & 5645.53 & 427.92 & 936.97 & 1944.42 & 1293.04 & 1115.36 \\
Building Height & 0 & 16.18 & 2.61 & 4.26 & 71.080 & 5.20 & 3.55 \\
\hline
\end{tabular}

Table 3. Pearson ( $r$ ) Correlation Matrix

\begin{tabular}{lccccc}
\hline Pearson Correlation & $\begin{array}{l}\text { Ethnic } \\
\text { diversity }\end{array}$ & Walkability & $\begin{array}{l}\text { Density of } \\
\text { NO2 air } \\
\text { emissions }\end{array}$ & $\begin{array}{l}\text { Building } \\
\text { Height }\end{array}$ & $\begin{array}{l}\text { Children } \\
\text { Density }\end{array}$ \\
\hline Ethnic diversity & 1,000 & & & & \\
Walkability & 0,468 & 1,000 & & & \\
$\mathrm{NO}_{2}$ Emissions Density & 0,516 & 0,558 & 1,000 & & \\
Building Height & 0,601 & 0,851 & 0,642 & 1,000 & 1,000 \\
Children Density & 0,498 & 0,787 & 0,319 & 0,725 & \\
\hline
\end{tabular}

Fig.1.c demonstrates the results of the walkability index (BWI). The walkability scores ranged significantly across the LOR spatial units and particularly between 0 (Forst Grunewald) and 0.88 (Donaustraae), while only one out of three geographical units presented scores greater than 0.5 (Table 2). Interestingly, the Hot-Spot analysis results (see Table 4 and Fig.1.d), demonstrated that about $46 \%$ of people resides in a statistically significant $(p<0.05)$ walkability hot spot, and on the other hand roughly $16 \%$ of the total inhabitants is located in statistically significant $(p<0.05)$ walkability cold spots. On average values, the most walkable boroughs were the central areas of Friedrichshain-Kreuzberg (0.51), and Mitte (0.48), where $100 \%$ and $90 \%$ respectively of their total population live in statistically significant walkability hot spots $(p<0.01)$. 
(a)

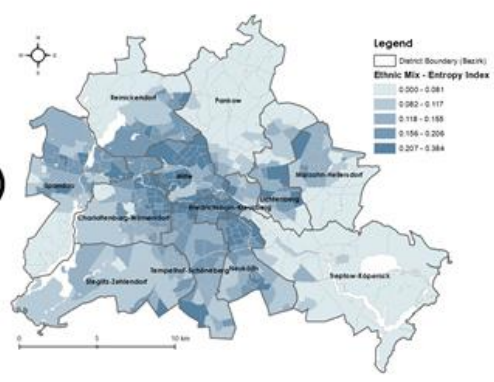

(c)

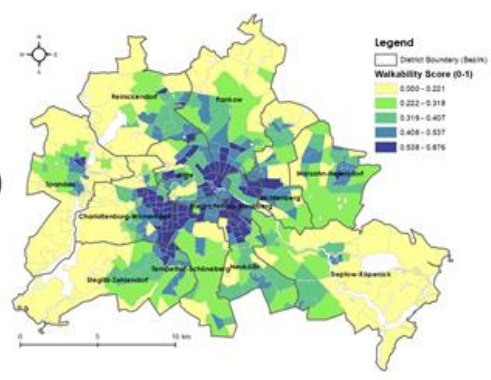

(e)

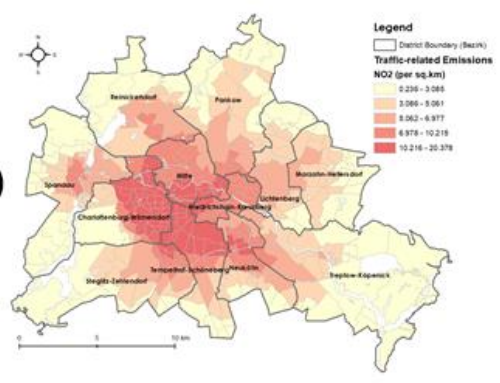

(g)

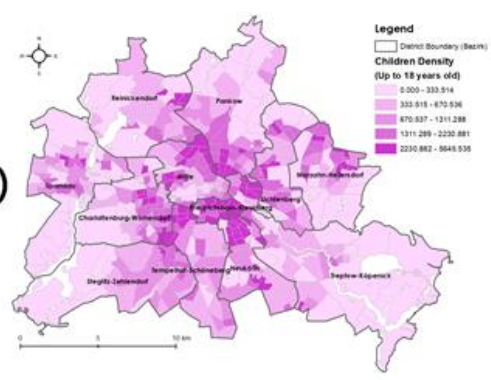

(i)

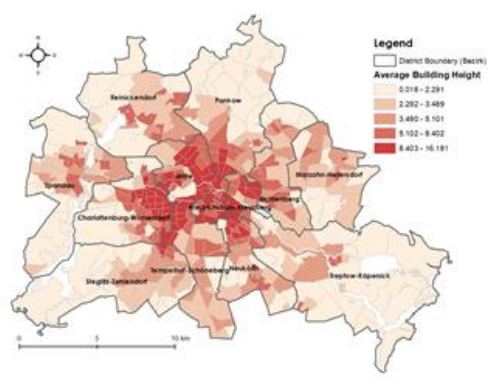

(b)

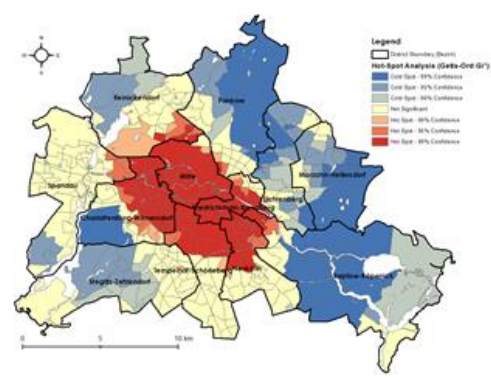

(d)

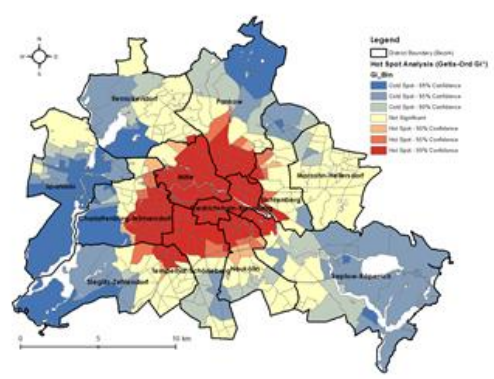

(f)

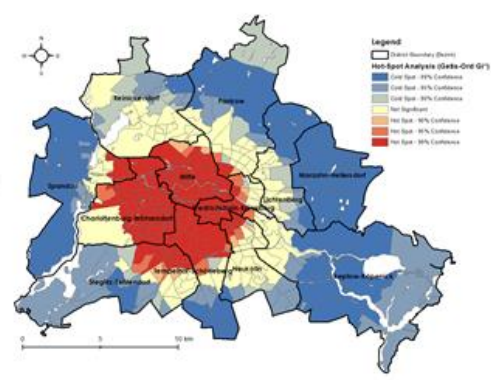

(h)

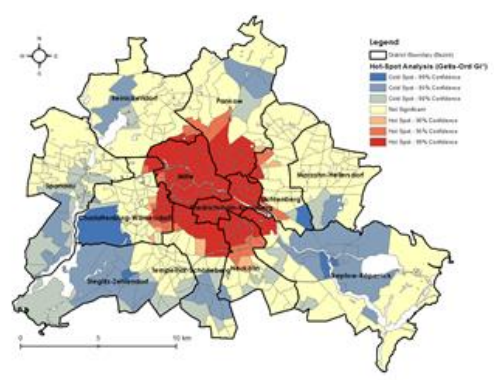

(j)

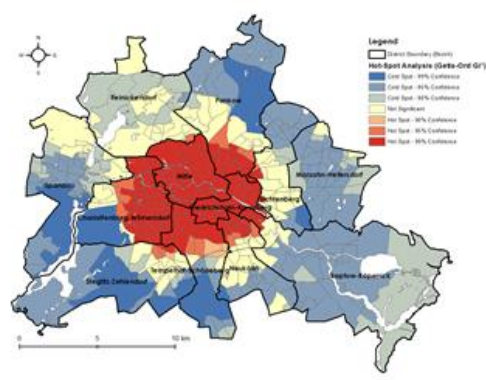

Figure 1. All maps provide results at LOR spatial units. (a) Average entropy index (ethnic mix), (b) Hot-Spot analysis of average entropy index (ethnic mix), (c) Average walkability (BWI) scores, (d) HotSpot Analysis of average walkability (BWI) scores, (e) Average $\mathrm{NO}_{2}$ air emissions, ( $f$ ) Hot-Spot analysis of average $\mathrm{NO}_{2}$ air emissions, ( $\mathrm{g}$ ) Auerage child density, (h) Hot-Spot analysis of average child density,

(i) Average building height, (j) Hot-Spot analysis of average building height 
To the contrary, the worst performing regions, based on average BWI scores, were those of the southeastern borough of Treptow-Köpenick (0.245) and the western borough of Spandau (0.246). About $83.6 \%$ and $41 \%$ of the total population in Spandau and Treptow-Köpenick, respectively live in statistically significant $(p<0.05)$ walkability cold spots (see Fig. 1.d). This evidence means that in Spandau, as well as in other western suburban areas with relatively low BWI scores, further analysis is required to crosscheck if these communities host people of limited mobility options (non-car owners) and lower socioeconomic status. Additionally, BWI scores were strongly and positively correlated (see Table 3 ) with all other exploratory variables such as average building height ( $r=0.85)$, child density ( $r=0.78)$, and $\mathrm{NO}_{2}$ emissions $(r=0.56)$.

The density of traffic-related $\mathrm{NO}_{2}$ air pollutants is depicted in Fig.1.e. and the values ranged between 0.23 (Müggelheim) and 20.37 (Lietzensee). On average, Charlottenburg-Wilmersdorf (12.66) showed the highest air pollution levels, while Marzahn-Hellersdorf (3.37) borough presented the lowest mean value in $\mathrm{NO}_{2}$ emissions density. However, about $54.4 \%$ of Berliners live in areas where the density of air emissions is beyond its median value. As can be seen in the hot-spot analysis map in Fig.1.f the pollutants are mainly concentrated in the central and southern areas of the urban core, while approximately all areas in the periphery and around the urban core were identified as cold spots. Except of children density where the association was week (see Table.3), the density of $\mathrm{NO}_{2}$ emissions is highly and positively correlated with all other variables (see Table 3).

Table 4. Share of population per Hot/Cold spot of BWI values

\begin{tabular}{lll}
\hline Walkability (BWI) Hot/Cold Spot & Population & \% in total Population \\
\hline Cold Spot - Confidence 99\% & 215668 & $5,97 \%$ \\
Cold Spot - Confidence 95\% & 364152 & $10,09 \%$ \\
Cold Spot - Confidence 90\% & 236089 & $6,54 \%$ \\
\hline Not Significant & 1072041 & $29,70 \%$ \\
\hline Hot Spot - Confidence 90\% & 76187 & $2,11 \%$ \\
Hot Spot - Confidence 95\% & 127914 & $3,54 \%$ \\
Hot Spot - Confidence 99\% & 1518105 & $42,05 \%$ \\
\hline
\end{tabular}

Regarding the building height variable, the highest values were found in Grosz-Platz (16.18) and Linden (15.94), while the lowest heights where demonstrated in highly nonbuilt-up areas, such as Grunewald (0.01) and Forst Grunewald (0.02) (Fig.1.i). Mitte (9.14) and Friedrichshain-Kreuzberg (8.19) boroughs, though, presented the highest average values of building height. Furthermore, the highest positive correlation of building height was stressed out with walkability ( $r=0.85)$, which is a highly expected result if we consider the built environment components of the BWI.

Child density was highest in Helmholtzplatz community with about 5645 kids per sq.km, while Messegel, Forst Grunewald, and Tegeler Forst showed almost zero values. Comparing the wider boroughs average densities, we found that FriedrichshainKreuzberg (2186) and Neukölln (1827) are the most children dense areas. On the other 
hand, Treptow-Köpenick, Spandau, and Steglitz-Zehlendorf, demonstrated density values lower than 1000 kids per sq.km. High children density values were mainly concentrated in central and central-northern areas, as in these areas the variable was identified as a statistically significant $(p<0.01)$ hot-spot (Fig.1.h). Finally, children density had the highest positive Pearson correlation with walkability score $(r=0.79)$.

\subsection{OLS results}

The OLS model explained about $43.91 \%$ (Adjusted $R^{2}$ ) of the variation of average ethnic diversity data in Berlin metropolitan area (see Table 5). Three out of the four exploratory variables, i.e., children density $(\beta=0.00002), \mathrm{NO}_{2}$ emissions density $(\beta=0.005)$, and building height, $(\beta=0.009)$ demonstrated a statistically significant, but weak, positive relationship with Berlin's ethnic diversity index, while walkability $(\beta=-$ $0.1594)$ presented the strongest and statistically significant negative relationship with the dependent variable (see Table 6). Thus, using the multiple regression method we see that the real relationship between walkability and ethnic diversity is negative and not as indicated in the simple Person correlation analysis (Table 3 ). This is the wellknown issue of the confounding and suppression effect in statistics (Mackinnon et al., 2000), according to which simple correlation or regression approaches might be misspecified.

Table 5. OLS Diagnostics

\begin{tabular}{llllll}
\hline Adjusted R & AICc & $\begin{array}{l}\text { Koenker (BP) } \\
\text { Statistic }\end{array}$ & $\begin{array}{l}\text { Joint Wald } \\
\text { Statistic }\end{array}$ & $\begin{array}{l}\text { Joint F } \\
\text { Statistic }\end{array}$ & $\begin{array}{l}\text { Jarque-Bera } \\
\text { Statistic }\end{array}$ \\
\hline 0,4391 & -1360.165 & $37.8262^{*}$ & $267.1989^{*}$ & $88.2947^{*}$ & $41.0373^{*}$ \\
\hline
\end{tabular}

$\left(^{*}\right)$ statistically significant $p$-value $(p<0.01)$

Table 6. Summary of OLS results (Dependent variable=Ethnic Diversity)

\begin{tabular}{|c|c|c|c|c|c|}
\hline Variable & Coefficient ( $\beta$ ) & Standard Error & t-statistic & $\begin{array}{l}\text { Robust } \\
\text { Probabilities }\end{array}$ & VIF \\
\hline Intercept & 0.090244 & 0.006463 & 13.962414 & $0.000000^{*}$ & ------ \\
\hline Walkability & -0.159479 & 0.030773 & -5.182505 & $0.000014^{*}$ & 4.839139 \\
\hline Children Density & 0.000024 & 0.000004 & 6.103051 & $0.000000^{*}$ & 3.037958 \\
\hline $\mathrm{NO}_{2}$ Emissions Density & 0.005493 & 0.000834 & 6.585935 & $0.000000^{*}$ & 1.908741 \\
\hline Building Height & 0.009166 & 0.001507 & 6.081754 & $0.000000^{*}$ & 4.638705 \\
\hline
\end{tabular}

$\left(^{*}\right)$ statistically significant: $p$-value $(p<0.01)$

Hence, this negative relationship means that for a $100 \%$ increase in the walkability index with all other variables remaining constant, the entropy index (0-1) will be reduced by -0.159 . Considering that currently half of the LOR spatial units have entropy values lower than $\mathbf{0 . 1 4}$, this result becomes extremely important for the urban and transport planning literature, because it is highlighting the difficulties to distribute in an equal way the benefits of walkable urbanism without pushing pressure in socially diverse and perhaps more socially vulnerable communities. Overall, the OLS model was statistically significant (Joint Wald \& F statistics $p$-values<0.01). However, we found 
that the modeled relationships were not consistent, since the Koenker (BP) statistic was statistically significant $(p<0.01)$, too. Additionally, the residuals were not normally distributed (Jarque-Bera statistic, $p$-value $<0.01$ ) and as a result the predictions of the OLS were biased. Finally, the Global Moran's I residuals test (see Fig.3.a) demonstrated clustered characteristics $(I=0.26, z$-score $=18.64$, $p$-value $<0.01)$, which means that OLS residuals are spatially dependent. As can be seen in the OLS residuals map (Fig.2.a) a great share of the eastern area is underestimated, while centrally located parts are overestimated in the model predictions. Therefore, an alternative model or other exploratory variables should be investigated.

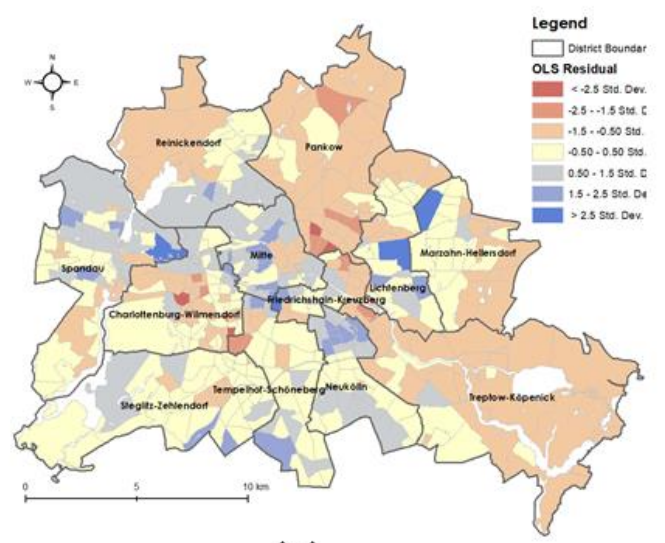

(a)

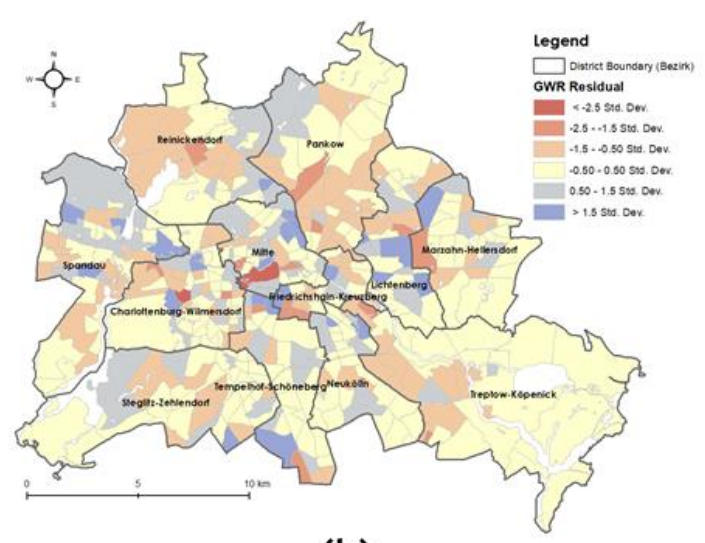

(b)

Figure 2. (a) OLS residuals Map, (b) GWR residuals Map

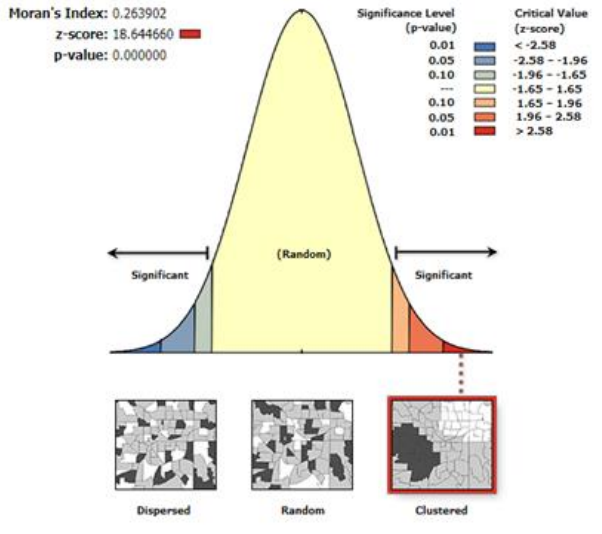

(a)

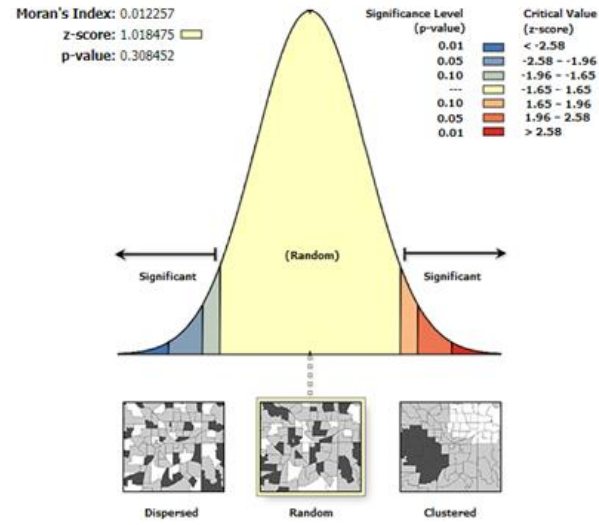

(b)

Figure 3. (a) OLS residuals Global Moran's I test, (b) GWR residuals Global Moran's I test

\subsection{GWR results}

The OLS residuals were spatially auto-correlated and thus the OLS model was unable to capture the spatial heterogeneity and non-stationarity of the data. A solution to analyze appropriately spatial non-stationarity from a local point of view is the GWR model (Fotheringham et al., 2002). Table 7 reports that the Adjusted $R^{2}$ value of GWR was 0.709 and higher than in the OLS (0.439). Consequently, the GWR model and in relation to the OLS explained substantially more variation in ethnic diversity data. 
Additionally, by comparing the AICc value of the OLS (Table 5) and GWR model (Table 7), we found that in the latter it was effectively reduced by 228 points. What is more, the residuals are depicted in the map of Fig.2.b and the results of the Global Moran's I residuals test are reported in Fig.3.b. On this basis, the GWR model is by far better than its OLS counterpart, since it showed a random pattern in the spatial distribution of its residuals. Furthermore, the Moran's I residuals test is close to zero, the $z$-score is almost 1 and this result is not statistically significant ( $p$-value>0.01). Consequently, we conclude that the GWR method removed the barriers of spatial dependent residuals and improved catalytically the predictive performance of the model.

Table 7. GWR Diagnostics

\begin{tabular}{llllll}
\hline & Neighbors & Sigma & AICc & $\mathbf{R}^{2}$ & Adjusted $\mathbf{R}^{\mathbf{2}}$ \\
\hline GWR & 63 & 0,0377 & $-1588,5988$ & 0,773823 & 0,709825 \\
\hline
\end{tabular}

Local $R^{2}$ values descriptive statistics are presented in Table 8 as well as in a map in Fig.4.a. These values interpret the performance of the applied local regression model. Thus, results closer to 1 indicate a perfect fit local equation. As can be seen in Table 8 local $R^{2}$ values ranged between 0.02 and 0.79 , and the median value was low at 0.39 . However, in half of the twelve boroughs (i.e., Reinickendorf, Neukölln, MarzahnHellersdorf, Mitte, Pankow, and Treptow-Köpenick) more than $25 \%$ of their LOR units presented local $R^{2}$ values greater than 0.5 , which means that in these areas the local model presented a higher goodness of fit.

Table 8. Summary statistics of GWR estimated coefficients (Dependent variable=Ethnic Diversity).

\begin{tabular}{lllllll}
\hline Independent Variables & Min. & Max. & Mean & $\mathbf{1}^{\text {st }} \mathbf{Q u}$. & Median & $\mathbf{3}^{\text {rd }} \mathbf{Q u}$. \\
\hline Intercept & -0.0311 & 0.3970 & 0.0958 & 0.0520 & 0.0811 & 0.1185 \\
Walkability & -0.4771 & 0.2068 & -0.1125 & -0.2089 & -0.1066 & -0.0039 \\
NO $_{2}$ Emissions Density & $-0,0137$ & 0,0311 & 0,0065 & 0,0022 & 0,0065 & 0,0131 \\
Children Density & -0.000027 & 0.000089 & 0.000024 & 0,000010 & 0,000021 & 0,000037 \\
Building Height & $-0,0111$ & 0,0220 & 0,0047 & 0,0001 & 0,0038 & 0,0085 \\
\hline Local R2 & 0.0252 & 0.7896 & 0.4015 & 0.2673 & 0.3864 & 0.5223 \\
\hline
\end{tabular}

Table 8 show the descriptive statistics of the estimated GWR coefficients and Table 9 presents the share of LOR spatial units per variable with statistically significant coefficients. On the other hand, the maps in Fig.4, illustrate statistically significant coefficients per variable. Thus, the darker blue the color it is the higher the strength of a positive relationship, while yellow colors demonstrate either strong negative relationships or weak positive associations. A first finding is that all exploratory variables, except of the intercept, demonstrated the symptoms of spatial heterogeneity. To wit, in some areas the coefficients were negative, but in other regions the coefficient values were identified as positive. However, in walkability and building height variables the positive and negative statistically significant coefficients were negligible at $\mathbf{0 . 4 5 \%}$ (Johannisthal West and Blumenuiertel) and $0.22 \%$ (Soldiner Str.) of the total number of LOR spatial units, respectively. In relation to the OLS model, the average 
coefficient values had the same relationship with ethnic diversity values, and the strength of each association remained almost similar.

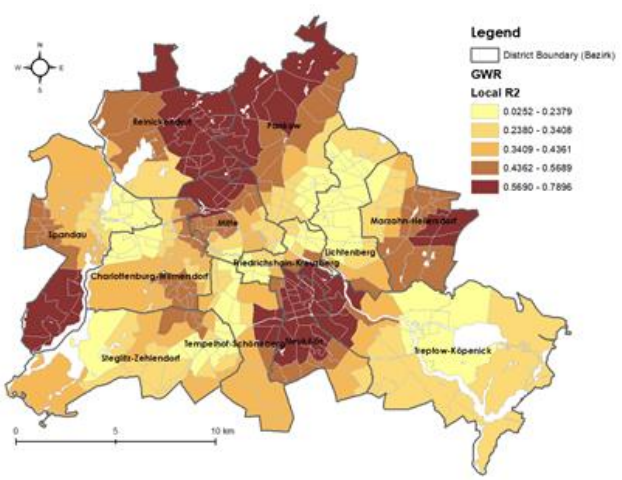

(a)

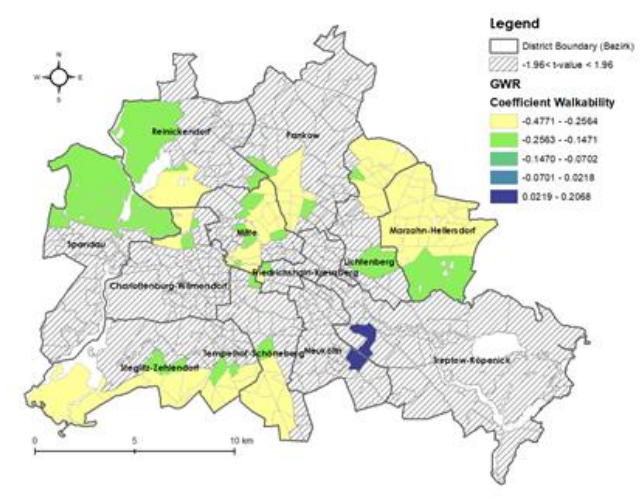

(c)

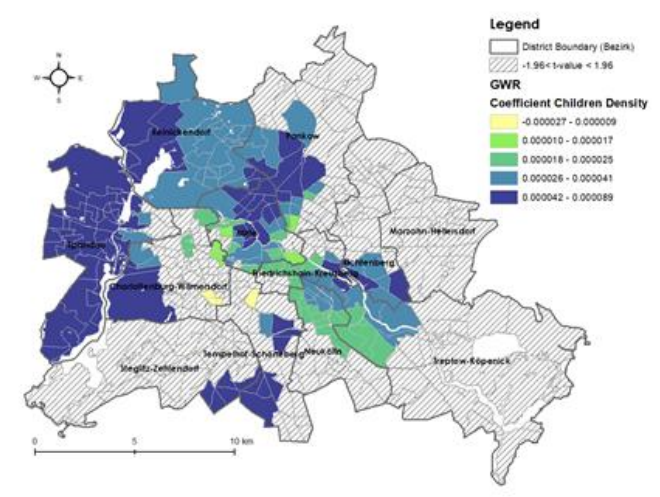

(e)

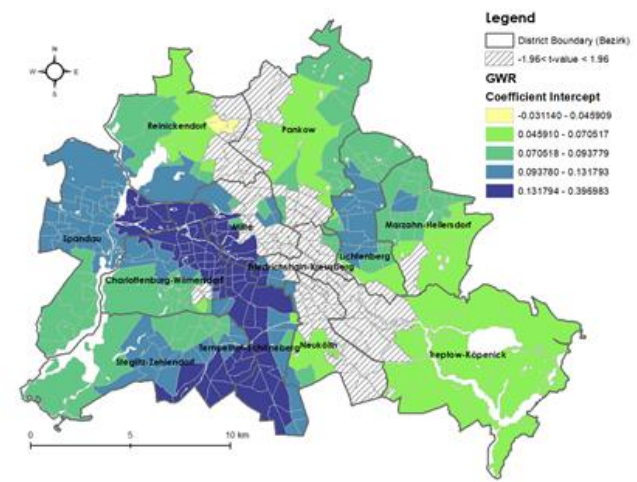

(b)

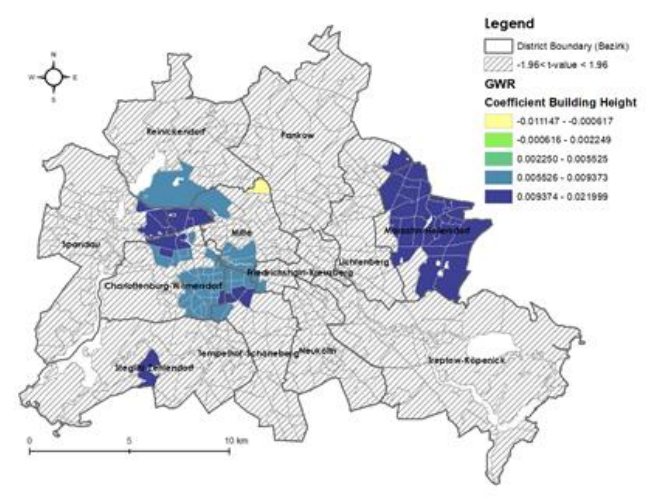

(d)

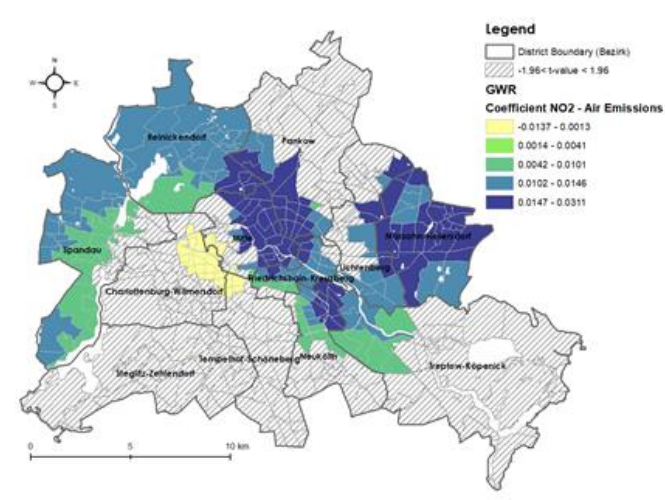

(f)

Figure 4. (a) Map of GWR Local $R^{2}$ results, (b) Map of GWR intercept results, (c) Map of GWR walkability coefficient values, (d) Map of GWR building height coefficient values, (e) Map of GWR children density coefficient values, (f) Map of $\mathrm{GWR} \mathrm{NO}_{2}$ air emissions coefficient values.

We found that only in $32.21 \%$ of the LOR spatial units the association of ethnic diversity and walkability is negative and statistically significant $(p<0.05)$. The stronger negative relationships though, indicated in Falkplatz (Pankow), Brunnenstr. (Mitte), and Arnimplatz (Pankow). Apart from some areas in the central city, all other 
statistically significant negative associations with walkability where identified in more suburban locations such as in Marzahn-Hellersdorf, Spandau, Steglitz-Zehlendorf and Tempelhof-Schöneberg. Therefore, this evidence might indicate that urban sprawl repair mechanisms in the outskirts of the city should be promoted cautiously, because that process might improve walkability levels and environmental sustainability, on the other hand it might create monocultural and homogenous societies. Moreover, as highlighted earlier only two neighborhoods in Treptow-Köpenick (Johannisthal West) and Neukölln (Blumenviertel) presented statistically significant positive relationships of walkability and ethnic mix, and they consist two examples of low density areas where further investigation is required to examine if future development of integrated walkability and social solutions there might finally lead in livable paradigms of socially diverse, walkable, and healthy communities.

Table 9. Share of areas with significant and not-significant (5\% significance level) GWR estimated coefficients.

\begin{tabular}{|c|c|c|c|}
\hline \multirow[b]{2}{*}{ Independent Variables } & \multicolumn{3}{|c|}{ t-Statistic (\% of LORs) } \\
\hline & $\begin{array}{l}\text { Negative Significant } \\
t \text {-ualues }<-1.95\end{array}$ & $\begin{array}{l}\text { Not Significant } \\
-195>t \text {-ualues }<1.95\end{array}$ & $\begin{array}{l}\text { Positive Significant } \\
\text { t-ualues }>195\end{array}$ \\
\hline Intercept & $0,00 \%$ & $25,95 \%$ & $74,05 \%$ \\
\hline Walkability & $32,21 \%$ & $67,34 \%$ & $0,45 \%$ \\
\hline $\mathrm{NO}_{2}$ Emissions Density & $6,04 \%$ & $46,09 \%$ & $47,87 \%$ \\
\hline Children Density & $1,12 \%$ & $55,70 \%$ & $43,40 \%$ \\
\hline Building Height & $0,22 \%$ & $79,19 \%$ & $20,58 \%$ \\
\hline
\end{tabular}

The association of ethnic diversity and $\mathrm{NO}_{2}$ air emissions density was positive and statistically significant $(p<0.05)$ in $47.87 \%$ of the LOR units. Again the strongest positive associations were found in neighborhoods around Gesundbrunnen area, which is between the administrative boundaries of Mitte and Pankow boroughs. Large parts of LOR units in Marzahn-Hellersdorf demonstrated also positive and strong relationships. Interestingly, in $6.04 \%$ of the LOR units the association between $\mathrm{NO}_{2}$ and ethnic diversity became negative and statistically significant $(p<0.05)$. These areas are currently highly diverse communities and almost all are concentrated in Charlottenburg-Wilmersdorf central borough. About $43.4 \%$ of the LOR spatial units presented positive and statistically significant $(p<0.05)$ associations between children density and ethnic diversity values. The highest coefficients were concentrated in the western outskirts and the northern parts of Spandau borough. However, about all coefficients were almost zero, which translates into a very weak relationship with ethnic mix. Furthermore, in three neighborhoods of Charlottenburg-Wilmersdorf area (i.e., Rathaus Wilmersdorf, Platz, straße) the density of children found to decrease the level of ethnic diversity. Finally, regarding the relationship of building height and ethnic mix, we found that only in $\mathbf{2 0 . 5 8 \%}$ of the LOR units the association is statistically significant and positive. The highest strength of this relationship was indicated in the eastern and more suburban parts of the Marzahn-Hellersdorf eastern borough. Consequently, these areas might be suitable for future housing development policies regarding new migrant housing estates. 


\section{DISCUSSION \& CONCLUSION}

This research applied a spatial regression modeling approach to explore the relationship of walkability and ethnic diversity in urban communities of the Berlin metropolitan area. Up to date, we do not have enough empirical evidence from Europe with respect to the impacts of walkable neighborhoods on supporting sustainable and multiethnic communities. To this end, our findings provide new insights that should problematize urban and transport planning researchers. Moreover, our results showed that the walkable urban form is not positively related to multiethnic communities. Thus, if walkability increases by $100 \%$ and all other variables remain constant then the ethnic mix indicator decreases by almost -0.16 , in other words it is reduced by two more points than the current median value (0.14) of the entropy index. This evidence proves that planning and design actions are not creating built environments that support efficiently socially diverse neighborhoods (Talen, 2012) and spatial inequalities might highly be driven by the walkability co-benefits. Although, the multiple spatial regression models did not control for the effects of housing prices (Kersting et al., 2017), but only controlled the influence of building height, the density of traffic-related emissions (i.e., $\mathrm{NO}_{2}$ ), and the density of children, we strongly believe that this negative interrelationship we have found might be also affected by underling gentrification (Quastel et al., 2012) processes happening in redeveloping areas with popular housing markets. Thus, multiethnic and diverse communities with vulnerable socioeconomic characteristics and with good urbanism features should be monitored so as to prevent any kind of future social sorting mechanisms which do not support social cohesion in the city. Interestingly, we also showed that multiethnic communities although they suffer from higher levels of NO2 emissions, they tend to have high-rise buildings (e.g., multistore apartment buildings), and they are attracted by higher densities in child populations. Therefore, high levels of air pollution, increased building density, less walkable urban forms and high presence of families with children are the most common built environment characteristics of multiethnic and diverse communities in Berlin.

With regard to walkability index results, we found that only one out of three LOR spatial units $(n=447)$ score more than $50 \%$ and the further you go from the city center the lower the walkability it is. What is more, about $16 \%$ of the population resides in clustered areas of pretty low walkability values. This phenomenon is mainly observed in the western and southeastern boroughs at the periphery of the city, where the symptoms of urban sprawl traumatize the good urbanism that walkability creates in the urban core area. However, taking into consideration the negative relationship of walkability with ethnic diversity, any new plan that aims to repair urban sprawl should be treated with caution, as homogenous or ghetto societies might be a risk factor in planning.

From a methodological perspective, our approach demonstrated that in our case simple regression can be misleading (Mackinnon et al., 2000), since the initially positive Pearson correlation coefficient of ethnic mix and walkability, was entirely reversed in the multiple linear regression model. Furthermore, the GWR regression method (Fotheringham et al., 2002) outperformed the misspecified OLS model, which suffered from spatially dependent residuals. GWR explained about $71 \%$ of the variation in ethnic diversity data, while the average strength of coefficients remained almost 
similar in relation to the OLS results. Additionally, the local nature of the GWR approach demonstrated the spatial heterogeneity of all exploratory variables, which means that all variables presented coefficient values of different signs in some areas than somewhere else. However, our findings showed that walkability affects ethnic diversity negatively only in $32.2 \%$ of LOR spatial units, as the reported relationships in all other areas were not statistically significant. Only two neighborhoods, though, indicated statistically significant positive correlations of ethnic mix and walkability, namely in Treptow-Köpenick (Johannisthal West) and Neukölln (Blumenviertel), and these areas might consist policy targets to create great paradigms in social and environmental sustainability.

Finally, while our methodological approach enriches the urban and transport planning literature with new insights on walkability and its social implications, it also has certain limitations. First, since aggregated data were utilized the well-known in the relevant literature modifiable areal unit problem (MAUP) can be an issue (Openshaw, 1984). Second, the BWI is not a verified measure of objectively measured pedestrian activity or physical activity data. Third, the scores of BWI are not directly comparable with other studies, since some variables use different data protocols (i.e., land use definitions). And finally, variables used in the spatial regression models refer to varying time frames.

This work promotes the idea that the planning practice can create cosmopolitan, walkable, and sustainable urban communities (Talen, 2012). In Berlin although this idea is not yet achieved there is a lot of room for policy improvements. To this end, future research could focus on analyzing the spatiotemporal inequities of walkability patterns as well as the role of walkability in gentrification and emerging housing markets in the city.

\section{ACKNOWLEDGEMENTS}

This research is co-financed by Greece and the European Union through the Programme "Human Resources Development, Education and Lifelong Learning" in the context of the project "Strengthening Human Resources Research Potential via Doctorate Research" (MIS-5000432), implemented by the State Scholarships Foundation (IKY).

\section{REFERENCES}

Amt für Statitstik Berlin Brandenburg. (2019). kleine berlin-statistik. Berlin. Retrieved from https://www.statistik-berlinbrandenburg.de/produkte/kleinestatistik/AP_KleineStatistik_DE_2019_BE.pdf

Apparicio, P. et al. (2014). An open-source software for calculating indices of urban residential segregation. Social Science and Computer Review, 32(1), 117-128. https://doi.org/10.1177/0894439313504539

Bartzokas-Tsiompras, A, \& Photis, Y.N. (2017). What matters when it comes to "walk and the city"? Defining a weighted GIS-based walkability index. Transportation Research Procedia, 24, 523-530. https://doi.org/10.1016/j.trpro.2017.06.001 
Bartzokas-Tsiompras, A. et al. (2020). Is walkability equally distributed among downtowners? Evaluating the pedestrian streetscapes of eight European capitals using a micro-scale audit approach. International Journal of Transport Development and Integration, 4(1), 75 - 92. https://doi.org/10.2495/TDI-V4-N1$\underline{75-92}$

Bartzokas-Tsiompras, A., \& Photis, Y. N. (2019). Measuring rapid transit accessibility and equity in migrant communities across 17 European cities. International Journal of Transport Development and Integration, 3(3), 245 - 258. https://doi.org/10.2495/TDI-V3-N3-245-258

Bartzokas-Tsiompras, A., et al. (2021). Addressing Street Network Accessibility Inequities for Wheelchair Users in Fifteen European City Centers, Advances in Intelligent Systems and Computing, 1278, pp.1022-1031. https://doi.org/10.1007/978-3-030-61075-3_98

Boyle, A. et al. (2014). Does Walkability Influence Housing Prices? Social Science Quarterly, 95, 852-867. https://doi.org/10.1111/ssqu.12065

Brownson, R.C. et al. (2009). Measuring the Built Environment for Physical Activity. State of the Science. American Journal of Preventive Medicine, 36(4 SUPPL.), S99S123.e12. https://doi.org/10.1016/j.amepre.2009.01.005

Brunsdon, C. et al. (1996). Geographically weighted regression: a method for exploring spatial nonstationarity. Geographical Analysis, 28(4), 281-298. https://doi.org/10.1111/j.1538-4632.1996.tb00936.x

Deng, C. et al. (2020). A data-driven framework for walkability measurement with open data: A case study of triple cities, New York. ISPRS International Journal of Geo-Information, 9(1), art. no. 36. https://doi.org/10.3390/ijgi9010036

Dong, H. (2017). Does walkability undermine neighbourhood safety? Journal of Urban Design, 22, 59-75. https://doi.org/10.1080/13574809.2016.1247644

Duncan, D.T. et al. (2011). Validation of Walk Score ${ }^{\circledR}$ for estimating neighborhood walkability: An analysis of four US metropolitan areas. International Journal of Environmental Research and Public Health, 8(11), 4160-4179. https://doi.org/10.3390/ijerph8114160

Duncan, D.T. et al. (2012). Space, race, and poverty: Spatial inequalities in walkable neighborhood amenities? Demographic Research, 26, 409-448. https://doi.org/10.4054/DemRes.2012.26.17

ESRI. (2020a). Interpreting GWR results. Retrieved 09 25, 2020, from https://desktop.arcgis.com/en/arcmap/10.3/tools/spatial-statisticstoolbox/interpreting-gwr-results.htm

ESRI. (2020b). Interpreting OLS results. Retrieved 09 25, 2020, from https://desktop.arcgis.com/en/arcmap/latest/tools/spatial-statisticstoolbox/interpreting-ols-results.htm 
Ewing, R., \& Cervero, R. (2010). Travel and the built environment. Journal of the American Planning Association, 76(3), 265-294. https://doi.org/10.1080/01944361003766766

Forsyth, A. (2015). What is a walkable place? The walkability debate in urban design. Urban Design International, 20(4), 274-292. https://doi.org/10.1057/udi.2015.22

Fotheringham, A.S. et al. (2002). Geographically weighted regression: The analysis of spatially varying relationships. West Sussex, England: John Wiley and Sons, Ltd.

Frank, L.D. et al. (2005). Linking objectively measured physical activity with objectively measured urban form: Findings from SMARTRAQ. American Journal of Preventive Medicine, 28 (2 SUPPL. 2), 117-125. https://doi.org/10.1016/j.amepre.2004.11.001

Frank, L.D. et al. (2006). Many pathways from land use to health: Associations between neighborhood walkability and active transportation, body mass index, and air quality. Journal of the American Planning Association, 72(1), 75-87. https://doi.org/10.1080/01944360608976725

Frank, L.D. et al. (2010a). Carbonless footprints: Promoting health and climate stabilization through active transportation. Preventive Medicine, 50, S99-S105. https://doi.org/10.1016/j.ypmed

Frank, L.D. et al. (2010b). The development of a walkability index: application to the Neighborhood Quality of Life Study. British Journal of Sports Medicine, 44, 924933. https://doi.org/10.1136/bjsm.2009.058701

Getis, A., \& Ord, J. (1992). The Analysis of Spatial Association by Use of Distance Statistics. Geographical Analysis, 24(3), 189-206. https://doi.org/10.1111/j.15384632.1992.tb00261.x

Gilderbloom, J.I. et al. (2015). Does walkability matter? An examination of walkability's impact on housing values, foreclosures and crime. Cities, 42(PA), 13-24. https://doi.org/10.1016/j.cities.2014.08.001

Grasser, G. et al. (2017). A European perspective on GIS-based walkability and active modes of transport. European Journal of Public Health, 27(1), 145-151. https://doi.org/10.1093/eurpub/ckw118

Gullón, P. et al. (2017). Intersection of neighborhood dynamics and socioeconomic status in small-area walkability: The Heart Healthy Hoods project. International Journal of Health Geographics, 16(1), art. no. 21. https://doi.org/10.1186/s12942017-0095-7

Habibian, M., \& Hosseinzadeh, A. (2018). Walkability index across trip purposes. Sustainable Cities and Society, 42, 216-225. https://doi.org/10.1016/j.scs.2018.07.005

Kely, C.M. et al. (2007). The association of sidewalk walkability and physical disorder with area-level race and poverty. Journal of Epidemiology \& Community Health, 61, 978-983. https://doi.org/10.1136/jech.2006.054775 
Kersting, S. et al. (2017, 29 07). Housing Shortage Gets Political. Retrieved 01 04, 2020, from Handelsblatt: https://www.handelsblatt.com/english/politics/merkel-usschulz-housing-shortage-gets-political/23571442.html?ticket=ST-3268716CakfuruokMqcuc2NyqqL-ap4

Knight, J. et al. (2018). Walkable and resurgent for whom? The uneven geographies of walkability in Buffalo, NY. Applied Geography, 92, 1-11. https://doi.org/10.1016/j.apgeog.2018.01.008

Koohsari, M.J. et al. (2019a). Natural movement: A space syntax theory linking urban form and function with walking for transport. Health and Place, 58, art. no. 102072. https://doi.org/10.1016/j.healthplace.2019.01.002

Koohsari, M.J. et al. (2019b). Walkability and walking for transport: Characterizing the built environment using space syntax. International Journal of Behavioral Nutrition and Physical Activity, 13(1), art. no. 121. https://doi.org/10.1186/s12966-016-0448-9

Lai, Y., \& Kontokosta, C. (2018). Quantifying place: Analyzing the drivers of pedestrian activity in dense urban environments. Landscape and Urban Planning, 180, 166178. https://doi.org/10.1016/j.landurbplan.2018.08.018

Leyden, K.M. (2003). Social Capital and the Built Environment: The Importance of Walkable Neighborhoods. American Journal of Public Health, 93(9), 1546-1551. https://doi.org/10.2105/A/PH.93.9.1546

Lund, H. (2002). Pedestrian environments and sense of community. Journal of Planning Education and Research, 301-312. https://doi.org/10.1177/0739456X0202100307

Mackinnon, D.P. et al. (2000). Equivalence of the Mediation, Confounding and Suppression Effect. Prevention Science, 1(4), 173-181. https://doi.org/10.1023/A:1026595011371

Millstein, R.A., et al. (2013). Development, scoring, and reliability of the Microscale Audit of Pedestrian Streetscapes (MAPS). BMC Public Health, 13(403). https://doi.org/10.1186/1471-2458-13-403

Nieuwenhuijsen, M., \& Khreis, H. (2016). Car free cities: Pathway to healthy urban living. Environment International, 94, 251-262. https://doi.org/10.1016/j.enuint.2016.05.032

OECD. (2018). Migration snapshot of the city of Berlin. In Working Together for Local Integration of Migrants and Refugees in Berlin. Paris: OECD Publishing. https://doi.org/10.1787/9789264305236-6-en

Openshaw, S. (1984). Ecological Fallacies and the Analysis of Areal Census Data. Environment \& Planning A: Economy \& Space, 16(1), 17-31. https://doi.org/10.1068/a160017

Ord, J., \& Getis, A. (1995). Local Spatial Autocorrelation Statistics: Distributional Issues and an Application. Geographical Analysis, 27(4), 286-306. https://doi.org/10.1111/j.1538-4632.1995.tb00912.x 
Paraskevopoulos, Y. et al. (2019). Exploring the impact of network configuration and transport accessibility on population dynamics. The case of Naxos island, Greece. European Journal of Geography, 10(4), 177-194.

Quastel, N. et al. (2012). Sustainability-As-Density and the Return of the Social: The Case of Vancouver, British Columbia. Urban Geography, 33(7), 1055-1084. https://doi.org/10.2747/0272-3638.33.7.1055

Riggs, W. (2016). Inclusively walkable: exploring the equity of walkable housing in the San Francisco Bay Area. Local Environment, 21(5), 527-554. https://doi.org/10.1080/13549839.2014.982080

Rode, P. et al. (2015). Toward New Urban Mobility: The case of London and Berlin. London: LSE Cities/Innoz. London School of Economics and Political Science. Retrieved from https:///secities.net/wp-content/uploads/2015/09/New-UrbanMobility-London-and-Berlin.pdf

Sallis, J.F., et al. (2016). Physical activity in relation to urban environments in 14 cities worldwide: A cross-sectional study. The Lancet, 387(10034), 2207-2217. https://doi.org/10.1016/S0140-6736(15)01284-2

Senate Department for the Environment, Transport \& Climate Protection. (2019). "Mobilität in Städten - System repräsentativer Verkehrsbefragungen (SrV) 2018" Mobilitätsdaten für Berlin auch bezirksweise. Berlin. Retrieved from https://www.berlin.de/sen/uuk/verkehr/verkehrsdaten/zahlen-undfakten/mobilitaet-in-staedten-sru-2018/

Senate Department for Urban Development \& the Environment. (2015). Urban Development Concept Berlin 2030. Berlin. Retrieved from https://www.stadtentwicklung.berlin.de/planen/stadtentwicklungskonzept/do wnload/strategie/BerlinStrategie Broschuere en.pdf

Senate Department for Urban Development \& the Environment. (2017). Mobility in the City. Berlin. Retrieved from https://www.berlin.de/sen/uuk/en/traffic/trafficdata/facts-and-figures/mobility-in-the-city-berlin-traffic-in-figures-2017/

Speck, J. (2018). Walkable City Rules: 101 Steps to Making Better Places. Washington, D.C.: Island Press.

Stevenson, M., et al. (2016). Land use, transport, and population health: estimating the health benefits of compact cities. The Lancet, 388(10062), 2925-2935. https://doi.org/10.1016/S0140-6736(16)30067-8

Su, S. et al. (2019). Auditing street walkability and associated social inequalities for planning implications. Journal of Transport Geography, 74, 62-76. https://doi.org/10.1016/j.jtrangeo.2018.11.003

Talen, E. (2012). Design for Diversity. London: Routledge.

Theil, H. (1971). A note on the measurement of racial integration of schools by means of informational concepts. Journal of Mathematical Sociology, 1(2), 187-194. https://doi.org/10.1080/0022250X.1971.9989795 
Thornton, C.M. et al. (2016). Disparities in pedestrian streetscape environments by income and race/ethnicity. SSM - Population Health, 2, 206-216. https://doi.org/10.1016/j.ssmph.2016.03.004

Tintori, G. et al. (2018). Diversity, residential segregation, concentration of migrants: a comparison across EU citis. Brussels: Joint Research Center - European Commission. https://doi.org/10.2760/823648

Twardzik, E. et al. (2019). Walk Score and objectively measured physical activity within a national cohort. J Epidemiol Community Health, 73, 549-556. https://doi.org/10.1136/jech-2017-210245

W.H.O. (2017). Towards more physical activity in cities. Copenhagen: World Health Organization Regional Office for Europe.

Wang, H., \& Yang, Y. (2019). Neighbourhood walkability: A review and bibliometric analysis. Cities, 93, 43-61. https://doi.org/10.1016/j.cities.2019.04.015

Weiss, R.L. et al. (2010). Promoting Active Urban Aging: A Measurement Approach to Neighborhood Walkability for Older Adults. Cities Environ., 1, 12.

White, M. (1986). Segregation and Diversity Measures in Population Distribution. Population Index, 52(2), 198-221. 